\title{
CAUSA DE PEDIR: OS FATOS, OS FUNDAMENTOS JURÍDICOS E O AFORISMO
} IURA NOVIT CURIA

\author{
Vinícius de Souza Sant'Anna ${ }^{1}$
}

\section{Resumo:}

$\mathrm{O}$ artigo analisa a causa de pedir no processo civil brasileiro. Inicialmente, estabelece o seu conceito e conteúdo. Em seguida, analisa as teorias da substanciação e da individuação, apontando por que se entende que no Brasil foi adotada aquela primeira. Depois, procura identificar quais são os fatos que realmente identificam a causa de pedir. Finalmente, diferencia fundamentos jurídicos de fundamentos legais, e demonstra como o aforismo iura novit curia permite que o Estado-juiz faça o reenquadramento dos fatos articulados na petição inicial em qualquer norma capaz de resultar as consequências jurídicas pretendidas pelo autor.

Palavras-chave: Causa de pedir; substanciação; individuação; fatos; fundamentos jurídicos; iura novit curia.

\section{GROUND OF ACTION: THE FACTS, THE LEGAL BASIS AND THE APHORISM IURA NOVIT CURIA}

\begin{abstract}
:
The article analyzes the ground of action in the Brazilian civil process. Initially, it establishes its concept and content. Then, it analyzes the theories of substantiation and individuation, pointing out why it is understood that in Brazil the first one was adopted. Then, it seeks to identify what are the facts that really identify the ground of action. Finally, it differentiates legal basis from legal grounds, and demonstrates how the aphorism iura novit curia allows the judge to reframing the facts articulated in the application in any rule capable of resulting in the legal consequences intended by the author.
\end{abstract}

Keywords: Ground of action; substantiation; individuation; facts; legal basis; iura novit curia.

\section{Introdução}

O trabalho versa sobre a causa de pedir e baseia-se no método indutivo de pesquisa, apoiando-se na revisão bibliográfica brasileira e estrangeira sobre a temática.

Inicialmente, o trabalho estabelece o conceito e o conteúdo da causa de pedir, tendo como ponto de partida o art. 319, inciso III, do Código de Processo Civil de 2015

\footnotetext{
${ }^{1}$ Mestrando em Direito Processual pela Universidade Federal do Espírito Santo. Especialista em Direito Processual Civil pela Faculdade de Direito de Vitória. Professor das disciplinas Teoria Geral do Processo e Direito Processual Civil na Faculdade Novo Milênio. E-mail: vinicius_santanna@outlook.com.
} 
(CPC/2015), que exige que na petição inicial sejam indicados os fatos e os fundamentos jurídicos do pedido.

Em seguida, é feita uma breve análise das teorias da substanciação e da individuação, demonstrando-se suas respectivas perspectivas sobre a causa de pedir. Além disso, são indicados os pontos positivos e negativos das teorias, bem como expostas as razões pelas quais se entende que o processo civil brasileiro filiou-se à substanciação.

Ato contínuo, considerando que na petição inicial podem ser articuladas alegações relevantes e de somenos importância para a individualização da demanda, o trabalho volta-se à análise do elemento fático da causa de pedir, procurando identificar quais são os fatos que realmente a identificam, denominados primários ou essenciais, e diferenciando-lhes daqueles cognominados secundários ou simples.

Mais adiante, o foco é direcionado ao elemento jurídico da causa de pedir que, apesar de não se prestar à sua identificação, deve constar da exordial por força da exigência contida no art. 319, inciso III, do CPC/2015. Nesse sentido, procura-se distinguir fundamentos jurídicos e fundamentos legais, bem como evidenciar de que maneira o aforismo iura novit curia permite que o Estado-juiz enquadre os fatos narrados pelo autor em outra categoria jurídica diversa daquela por ele apontada.

Ao final, o trabalho conclui que no Brasil o Estado-juiz tem ampla liberdade para, ao emoldurar as alegações fáticas do demandante em qualquer norma capaz de resultar as consequências jurídicas pretendidas, tornar essenciais fatos inicialmente considerados simples, e vice-versa, impondo-se apenas a observância do contraditório prévio, dos fatos articulados e do pedido deduzido.

\section{Causa de pedir: conceito e conteúdo}

Ao lado das partes e do pedido, a causa de pedir constitui elemento de identificação da demanda, sendo considerado o mais controvertido deles (CANOVA, 1980, p. 16).

Temos para nós que a expressão causa de pedir é autoexplicativa, permitindo, grosso modo, a intuição de que se trata da causa, motivo ou fundamento pelo qual o demandante formula determinado pedido.

Sendo assim, quem pretende obter tutela jurisdicional com vistas a alcançar determinado resultado prático capaz de modificar a sua realidade (bem da vida), precisa trazer 
ao conhecimento do Estado-juiz, além da sua pretensão processual (pedido mediato e pedido imediato), algumas informações de extrema importância para que o julgamento seja levado a cabo, pois elas indicam por que algo é pretendido pelo demandante.

Esse modo simplório de enxergar a causa de pedir é apenas um ponto de partida para a sua compreensão, visto que seu conteúdo, por ser demasiadamente complexo, já foi alçado pela doutrina a um dos temas mais densos em direito processual (MESQUITA, 2005, p. 141).

A compreensão da causa de pedir como sendo o fundamento do pedido está alinhada a uma fórmula tradicionalmente adotada pelo direito processual brasileiro (art. 158, inciso III, do CPC/1939; art. 282, inciso III, do CPC/1973; art. 319, inciso III, do CPC/2015), consistente na exigência de que a petição inicial, como veículo da demanda, atenda a determinados requisitos. Dentre esses requisitos, encontra-se a necessidade de indicação dos fatos e dos fundamentos jurídicos do pedido, o que evidencia a composição mista da causa petendi.

É o que sustenta Dinamarco (2019, p. 151):

\begin{abstract}
Todo direito a um determinado bem da vida nasce necessariamente de dois elementos: um preceito que a lei preestabelece e um fato previsto na lei como antecedente lógico da imposição do preceito (ex facto oritur jus). Em toda norma jurídica existe uma previsão genérica e abstrata de fatos tipificados como maior ou menor precisão (fattispecie), seguida do preceito a aplicar cada vez que na vida concreta das pessoas ou grupos venha a acontecer um fato absorvido nessa previsão (sanctio juris). Por isso, para coerência lógica com o sistema jurídico como um todo, o sujeito que postula em juízo deve obrigatoriamente explicar os fatos que lhe teriam dado direito a obter o bem e o preceito pelo qual esses fatos geram o direito afirmado. Isso explica a composição mista da causa petendi, indicada no Código de Processo Civil como fatos e fundamentos jurídicos do pedido.
\end{abstract}

A partir desse esquema, a doutrina classifica a causa de pedir em próxima e remota: esta, concernente aos fatos; aquela, referente aos fundamentos jurídicos (SANTOS, 2008, p. 146; DINAMARCO, 2019, p. 151).

É válido o registro, porém, de que há quem inverta estes termos, enxergando a causa de pedir próxima como sendo os fatos e a causa de pedir remota como sendo os fundamentos jurídicos (CÂMARA, 2013, p. 356; ABELHA, 2016, p. 464).

Embora essa estruturação da causa petendi possa, à primeira vista, parecer singela, dela decorrem diversos problemas relacionados às demandas, sobretudo no que tange à preponderância dos fatos ou dos fundamentos jurídicos na sua identificação, o que torna necessária a compreensão das teorias da substanciação e da individuação. 


\section{Teorias da substanciação e da individuação}

Vimos no item precedente que a causa de pedir é composta pelos fatos e pelos fundamentos jurídicos. Agora, convém investigarmos se, na identificação da causa petendi, há a preponderância de um destes elementos, visto que, a depender da resposta encontrada, pode haver interferência direta sobre diversas figuras processuais, tais como a estabilização da demanda e os limites da coisa julgada e da sua eficácia preclusiva.

Essa investigação nos conduz, inevitavelmente, ao estudo de duas teorias que se desenvolveram na tradição romano-germânica com o propósito de deslindar o que exatamente identifica a causa de pedir. Trata-se das teorias da substanciação e da individuação, alvo de intenso debate na Alemanha e na Itália em virtude da imprecisão dos seus textos legislativos ${ }^{2}$.

Segundo a substanciação, a causa de pedir é identificada pelos fatos que constituem o direito alegado pelo demandante (CANOVA, 1980, p. 46; RICCI, 1995, p. 1232-1233).

Para esta teoria, não há a necessidade de qualificação dos fatos narrados para fins de identificação da causa petendi, de modo que, caso isso seja feito, mesmo que de maneira equivocada, problema algum haverá, pois o respectivo enquadramento é tarefa que incumbe ao juiz, que conhece o direito (LEONEL, 2006, p. 88, OLIVEIRA, B., 2007, p. 40).

Por sua vez, de acordo com a individuação, a causa de pedir não se consubstancia na alegação de fatos constitutivos, mas na identificação do direito que deles decorrem (CANOVA, 1980, p. 46; RICCI, 1995, p. 1228-1229). Assim, a identificação da causa petendi é feita a partir da individualização do direito material no qual se baseia o pedido da parte autora, abstraindo-se os fatos que o originam (OLIVEIRA, B., 2007, p. 41).

\footnotetext{
${ }^{2}$ Da maneira como é analisada atualmente, a problemática tem início, resumidamente, com a entrada em vigor da ZPO alemã de 1879. No período anterior ao advento da referida lei processual, o processo germânico era caracterizado pela existência de fases preclusivas bastante claras. A regra da eventualidade impunha que, já no libelo, todos os fatos constitutivos do direito do demandante fossem alegados, não sendo suficiente, para fins de identificação da demanda, a simples indicação da relação jurídica na qual o pedido se pautava. Enxergava-se, assim, a preponderância dos fatos na identificação da demanda, em consonância com as ideias imanentes à teoria da substanciação. No entanto, a partir da vigência da ZPO de 1879, os processualistas alemães passaram a entender que, em virtude da alusão feita, em seu $\S 230$, ao fundamento da pretensão deduzida, a regra da eventualidade havia sido rebaixada a um segundo plano, ao menos que tange às ações fundadas em direito reais, permanecendo a exigência de indicação dos fatos constitutivos somente para as ações fundadas em direitos obrigacionais. A polêmica também teve desdobramentos na Itália, tendo em vista as sucessivas reformas processuais ocorridas em 1942, 1950, 1973 e 1990, com idas e vindas do legislador no tocante ao estabelecimento da necessidade de maior ou menor especificação dos fatos, levando os processualistas daquele país a discutir qual dos elementos (de fato ou de direito) deveria preponderar na identificação da causa petendi (TUCCI, 2001, p. 90-140; LEONEL, 2006, p. 86-99; OLIVEIRA, B., 2007. p. 39-55).
} 
Resumidamente, o que contribui para a identificação da causa de pedir, sob ponto de vista da teoria da substanciação, é o fato constitutivo do direito alegado, ao passo que, sob a ótica da teoria da individuação, a causa petendi é especificada pelo direito afirmado pelo autor, que constitui consequência daqueles fatos.

Fincadas essas ideias, pode-se perceber que, adotada a teoria da substanciação, diferentes fatos constitutivos darão origem a diferentes causas de pedir. É por isso que, com estabilização da demanda, não se mostra possível alterar as alegações fáticas inicialmente afirmadas, pois do contrário haveria modificação da causa petendi (LEONEL, 2006, p. 88; SIQUEIRA, 2018, p. 119).

Por outro lado, revela-se possível o ajuizamento de nova demanda na qual se deduza o mesmo pedido formulado em demanda anterior, contanto que amparada em fatos constitutivos diversos (em causa de pedir diferente, portanto), não se podendo cogitar, neste caso, de repetição de demandas, dada a ausência de tríplice identidade. Porém, se a nova demanda diferenciar-se da anterior somente no que tange à relação jurídica, repetindo-se os mesmos fatos constitutivos, não será admitida, por caracterizar litispendência ou coisa julgada, conforme o caso (SIQUEIRA, 2018, p. 119).

A seu turno, adotada a teoria da individuação, os fatos constitutivos inicialmente alegados poderão ser modificados no curso do processo, visto que não se prestam à identificação e à modificação da causa de pedir (RICCI, 1995, p. 1232).

Assim, não se revela possível a propositura de nova demanda baseada na mesma relação jurídica ou o no mesmo direito afirmado em demanda anterior, ainda que amparada em fatos constitutivos diversos.

É o que sustenta Leonel (2006, p. 88-89):

\begin{abstract}
Já na teoria da individuação da demanda, como esta se identifica pelo conteúdo do direito deduzido, ficam absorvidos todos os fatos que servem à sustentação do direito invocado em juízo. Inviabiliza-se que, em ulterior ação, seja formulada a mesma pretensão, com amparo em fatos já existentes na época da primeira ação, ainda que não alegados. Aqui, os fatos servem apenas para a prova do direito alegado, não para sua identificação.
\end{abstract}

Para exemplificar, imaginemos que seja proposta uma demanda reivindicatória na qual o autor tenciona obter a posse de um bem imóvel, adquirido de terceiro e cuja transmissão de propriedade afirma ter sido levada a efeito perante o registro imobiliário. 
Sob o enfoque da teoria da substanciação, a causa de pedir assenta-se no fato constitutivo do direito de propriedade alegado pelo autor, qual seja, o registro imobiliário. Por tal razão, após a estabilização da demanda, não será possível invocar outro fato constitutivo do direito de propriedade, como, por exemplo, a usucapião.

Nada impedirá, porém, que no caso de insucesso na primeira demanda, a usucapião seja deduzida em outra, que se diferenciará da demanda anterior porque as causas de pedir serão distintas, já que os fatos constitutivos serão diversos.

Porém, sob o enfoque da teoria da individuação, a causa petendi, no exemplo proposto, consubstancia-se no direito de propriedade, pouco importando, para fins de identificação da demanda, como se deu a aquisição da coisa. Assim, a alegação de novos fatos constitutivos, tais como a usucapião, em nada modificaria a causa de pedir. Todavia, transitando em julgado sentença que rejeite a pretensão inicial, o autor não poderá propor novas demandas visando reconhecer o direito de propriedade que já lhe foi negado, ainda que se valha de outros fatos constitutivos.

É possível vislumbrar pontos positivos e negativos nas duas teorias.

A teoria da substanciação acelera a marcha processual e garante que ela não retroceda, dada a sua rigidez, na medida em que estabelece um momento processual a partir do qual não será possível alegar novos fatos constitutivos, tendo em vista a estabilização da demanda. No entanto, peca por não resolver toda a crise de direito material, que poderá ser reavivada em outra demanda, desde que pautada em diferente causa de pedir (isto é, fato constitutivo diverso). Já a teoria da individuação, por ser maleável, permite que, ao longo da marcha processual, haja modificação dos fatos constitutivos inicialmente alegados. Em razão dessa circunstância, o desfecho da causa pode prolongar-se demasiadamente, muito embora se tenha, ao final do processo, a resolução definitiva da crise jurídica relativa ao direito deduzido em juízo (LEONEL, 2006, p. 88-89; LOPES, 2012, p. 56-57 SIQUEIRA, 2018, p. 120-121).

Convém frisar que não é possível apontar, de maneira abstrata, que uma teoria seja mais eficiente do que a outra, na medida em que ambas deixam em aberto a possibilidade de que a crise jurídica debelada em demanda anterior seja novamente trazida a juízo, contanto que alterados os fatos constitutivos (na teoria da substanciação), ou a relação jurídica ou direito afirmado (na teoria da individuação). Assim, somente a análise das particularidades do caso concreto poderá revelar qual das teorias se mostrou mais eficiente, tendo-se por referência aquele caso específico (LOPES, 2012 p. 56-57). 
Além disso, não se pode ignorar que a adesão a uma ou outra teoria é opção políticolegislativa de cada país, sendo inevitável que a escolha feita acabe por revelar vantagens e desvantagens (OLIVEIRA, B., 2007, p. 54).

Finalmente, é importante o registro de que aqueles que comungam da individuação não ignoram que, a depender da natureza do direito material discutido em juízo, a identificação da causa de pedir e da demanda dependerá da narrativa do fato constitutivo do direito alegado, tal como se passa na substanciação, daí por que já se chegou a afirmar que as duas teorias figuram como faces de uma mesma realidade (FAZZALARI, 1957, p. 118).

\section{Adoção da teoria da substanciação pelo direito brasileiro}

Impende frisar, desde já, que o CPC/2015 não esclarece (pelos menos não de maneira textual) se ele adotou a teoria da substanciação ou a teoria da individuação. Nada obstante, diversos doutrinadores pátrios posicionam-se firmemente no sentido de que teríamos aderido à substanciação (BARBOSA MOREIRA, 2001, p. 17; CÂMARA, 2013, P. 264).

Alguns desses doutrinadores sustentam que a nossa filiação à substanciação estaria relacionada à circunstância de a legislação processual civil em vigor (art. 319, inciso III, do CPC/2015) - assim como faziam os códigos que lhe antecederam (no art. 158, inciso III, do CPC/1939 e no art. 282, inciso III, do CPC/1973) - exigir a indicação, na petição inicial, dos fatos e dos fundamentos jurídicos do pedido (PONTES DE MIRANDA, 1974, p. 17; ALVIM, 2005, p. 2005; BUENO, 2007, p. 366).

Mas seria essa uma razão suficiente para justificar a nossa adesão à substanciação? Parece-nos que não, visto que o art. 319, inciso III, do CPC/2015 aponta como requisito da peça inaugural tanto os fatos quanto os fundamentos jurídicos, sem indicar a existência de preponderância de um ou outro elemento.

Aliás, a literalidade do referido enunciado legislativo é capaz de nos conduzir à ilação de que no Brasil se adotou uma posição de equilíbrio entre as duas teorias, de modo que seria relevante, para fins de identificação da causa de pedir, não só os fatos, mas também os fundamentos jurídicos (MESQUITA, 2005, p. 154-155; DOMIT, 2018, p. 249-250). Mas essa também não nos parece ser a posição mais acertada, conforme veremos a seguir. 
É preciso buscar, então, para além daquilo que consta no art. 319, inciso III, do CPC/2015, outras razões capazes de demonstrar, com segurança, a nossa adesão a uma ou outra teoria.

Acreditamos que, a partir de uma análise sistemática de algumas posições assumidas pelo processo civil pátrio, é possível concluir que nos filiamos à teoria da substanciação. Tais posições, segundo nos parece, consistem na adoção: i) da regra da eventualidade; ii) de um rígido sistema de preclusões quanto à estabilização objetiva da demanda; iii) do aforismo iura novit curia.

A adoção da regra da eventualidade é tradicional no direito processual civil brasileiro, se fazendo presente no CPC/1939 (arts. 180 e 181), no CPC/1973 (arts. 264, 294 e 303) e também no CPC/2015 (arts. 329 e 342).

De acordo com tal regra, sobre as partes recai o dever de apresentar, até determinado momento processual, todos os meios de ataque e de defesa, sob pena de não poderem mais fazê-lo em outra oportunidade, naquele mesmo processo (TUCCI, 2001, p. 148).

Por meio da regra da eventualidade, impõe-se aos litigantes que apresentem seus argumentos de maneira clara e precisa já no início do processo, com o objetivo de evitar artimanhas procrastinatórias e a ocultação de fatos que só viriam a ser revelados ao final da tramitação processual (OLIVEIRA, C., 1997, p. 173-174; BARROS TEIXEIRA, 2005, p. 25).

Segundo pensamos, a regra da eventualidade não se acha adstrita ao réu (embora seja mais comumente estudada em relação à contestação), mas também se estende ao autor, estabelecendo que deduza suas alegações de fato no momento inicial do processo, preferencialmente na petição inicial (OLIVEIRA, B., 2007, p. 266-267).

Se há necessidade de o demandante concentrar suas alegações fáticas no início do processo, também deve haver o estabelecimento de um marco processual a partir do qual não será mais possível alterar os fatos narrados. Se assim não fosse, careceria de sentido a exigência de apresentação concentrada dos fatos no início do processo.

Nesse sentido, o art. 329 do CPC/2015 estabelece que o autor poderá, até a citação, alterar livremente o aspecto fático da causa de pedir, sem a necessidade de aquiescência do réu (inciso I). Após a citação e até o momento antecedente ao saneamento do processo, a modificação das alegações fáticas dependerá da concordância do demandado (inciso II). Porém, uma vez saneado o feito, não mais será possível modificar os fatos que compõem a causa petendi, independentemente de consentimento do réu (inciso II). 
A vedação de que o autor alegue fatos novos depois da estabilização objetiva da demanda está diretamente atrelada à circunstância de que, se isso fosse possível, haveria modificação da causa de pedir, o que acabaria por retardar a marcha processual, na medida em que permitiria retrocessos para que o contraditório e a ampla defesa pudessem ser realizados no que tange às novas alegações introduzidas no processo. Essa parece ser uma vantagem proporcionada pela regra da eventualidade e pela rigidez na estabilização da demanda.

No entanto, não há como desconsiderar a existência de uma desvantagem, consistente na possibilidade de a crise de direito material poder ser reavivada em outra demanda, pautada em fatos diversos daqueles invocados na demanda anterior e que, por isso mesmo, não se acharão abrangidos pela coisa julgada (LOPES, 2012, p. 56).

É por isso que nos parece apropriado afirmar que "a concentração dos atos processuais, decorrente da aplicação da regra da eventualidade, representa ao mesmo tempo garantia e obstáculo a um processo justo, adequado para refletir da melhor maneira possível a situação jurídica fora do processo" (OLIVEIRA, C., 1997, p. 173).

Percebe-se, portanto, que se adota no Brasil um rígido sistema de preclusões quanto à estabilização objetiva da demanda, sendo este um forte indício de filiação à teoria substanciação (SIQUEIRA, 2018, p. 132). Aliás, já se chegou a afirmar que essa rigidez é pressuposto da referida teoria (TUCCI, 2001, p. 151; LOPES, 2012, p. 56).

Há, ainda, uma terceira razão que nos leva a crer que nos filiamos à teoria da substanciação. Trata-se do aforismo iura novit curia.

Já vimos (item 2, supra) que a definição da causa de pedir, segundo a substanciação, é feita a partir dos fatos constitutivos do direito alegado pelo demandante, não estando o Estado-juiz vinculado aos fundamentos jurídicos invocados.

Muito embora não haja na nossa legislação processual regra expressa versando sobre o aforismo iura novit curia, é amplamente defendido pela doutrina brasileira que o acolhemos entre nós e que ele permite que Estado-juiz julgue os pedidos formulados valendo-se de qualificação jurídica diversa daquela que o demandante realizou, contanto que respeitados os fatos afirmados (BARBOSA MOREIRA, 2001, p. 17; TUCCI, 2001, p. 2001; SANTOS, 2008, p. 147; SICA, 2011, p. 93-94).

Diz-se que "a invocação dos fundamentos jurídicos na petição inicial não passa de mera proposta ou sugestão endereçada ao juiz, ao qual compete fazer depois os enquadramentos adequados" (DINAMARCO, 2019, p. 153). 
Assim, cremos que a análise sistemática do processo civil pátrio, que perpassa pela constatação de termos adotado (i) a regra da eventualidade, (ii) um sistema rígido de preclusões quanto à estabilização objetiva da demanda e (iii) o aforismo iura novit curia, leva-nos a concluir, de modo seguro, que nos filiamos à teoria da substanciação.

Dessa forma, a identificação da causa petendi, no Brasil, deve ser feita a partir dos fatos constitutivos do direito alegado pelo demandante.

Exatamente por isso, as alegações fáticas que não tenham sido deduzidas em uma determinada demanda poderão ser apresentadas em outra, ainda que ambas versem sobre o mesmo pedido mediato (resultado prático ou bem da vida). E assim o é porque, mudando-se os fatos, muda-se a causa de pedir e, consequentemente, muda-se a demanda.

\section{Causa de pedir remota: fatos essenciais e fatos secundários}

Conforme ressaltado anteriormente, o art. 319, inciso III, do CPC/2015 aponta como indispensável à petição inicial a indicação dos fatos e dos fundamentos jurídicos do pedido, os quais correspondem, respectivamente, às causas de pedir remota e próxima.

Em virtude da filiação do direito processual civil brasileiro à teoria da substanciação conforme visto anteriormente (item 3, supra), a causa de pedir deve ser identificada tão somente pelos fatos narrados, não se prestando a tal finalidade os fundamentos jurídicos, que constituem simples proposta ou sugestão endereçada ao Estado-juiz sobre como a contenda a ele trazida pode ser solucionada.

De acordo com a doutrina, a causa de pedir remota ou fática apresenta dois aspectos, denominados ativo e passivo: aquele, representado pelas informações relativas à existência do direito alegado; este, retratado pelas informações concernentes à necessidade de obtenção da tutela jurisdicional em relação a um determinado direito (BARBOSA MOREIRA, 2001, p. 15; OLIVEIRA, B., 2007, p. 38; DINAMARCO, 2019, p. 151-152).

Mais claramente dizendo, o aspecto ativo diz respeito ao fato constitutivo do direito alegado pela demandante, ao passo que o aspecto passivo refere-se ao fato do demandado que evidencia uma lesão ou ameaça a esse direito, daí se originando o interesse processual ou interesse de agir (TUCCI, 2001, p. 154).

Logo se vê que a causa de pedir passiva é importante não só para justificar o pedido do demandante, mas também para demonstrar seu interesse de agir, visto que, inexistindo 
lesão ou perigo de lesão a um direito seu, não fará sentido a movimentação da máquina judiciária.

Embora a causa petendi seja identificada pelo seu elemento fático, não são todos os fatos alegados pelo demandante que se prestam a tal finalidade. É dizer, "há um fato ou um núcleo de fatos que dá configuração mínima e elementar à causa de pedir” (TALAMINI, 2005, p. 77), e outros que: i) não passam de argumentos retóricos; ii) relacionam-se a indícios de prova de outros fatos; iii) referem-se à técnica processual; iv) não possuem relação alguma com o pedido formulado (SIQUEIRA, 2018, p. 135).

Assim, faz-se necessário distinguir, dentre as alegações fáticas formuladas pelo demandante, quais se referem a fatos principais ou essenciais e quais dizem respeito a fatos secundários ou simples.

Os fatos essenciais são aqueles capazes de produzir os efeitos jurídicos aspirados por meio do pedido que foi deduzido, haja vista preencherem o suporte fático da norma jurídica que será utilizada no caso. A seu turno, os fatos secundários ou simples, por critério de exclusão, são todos aqueles que não são capazes de justificar a produção das consequências jurídicas almejadas por intermédio do pedido formulado, visto não se enquadrarem no antecedente da norma a ser empregada no caso (TUCCI, 2001, p. 153; TALAMINI, 2005, p. 77-79; LOPES, 2012, p. 59; DOMIT, 2018, p. 266-267; LUCCA, 2018, p. 308-309).

Dos fatos essenciais decorre, de forma direta, a procedência ou improcedência do pedido apresentado (LUCCA, 2018, p. 308), sendo, por isso mesmo, fatos jurídicos, isto é, carregados de efeitos pelo ordenamento jurídico (CARVALHO, 1992, p. 81; CHIOVENDA, 1998, p. 22; LIEBMAN, 2005, p. 216).

São estes fatos que, por identificarem a causa de pedir, se submetem ao princípio da demanda, à regra da eventualidade, à estabilização objetiva da demanda e à regra da correlação. É dizer, não podem ser conhecidos de ofício, devem ser deduzidos no início do processo, sob pena de preclusão, e precisam ser estritamente observados pelo Estado-juiz por ocasião do julgamento (MACHADO, 2015, p. 91).

Dos fatos simples, por sua vez, não decorre a legitimidade ou ilegitimidade do pedido formulado, ainda que tenham ligação com aspectos probantes e com a técnica processual. Por tal razão, não se submetem ao mesmo regime jurídico que os fatos essenciais, daí por que podem ser considerados oficiosamente pelo Estado-juiz caso tenha tomado ciência deles a partir de outros elementos dos autos, vedando-se apenas a utilização da ciência privada 
e impondo-se o respeito ao contraditório (MACHADO, 2015, p. 91-92; LUCCA, 2018, p. 309-311; SIQUEIRA, 2018, p. 138).

Para exemplificar, imaginemos que Mário proponha uma demanda em face de Pedro, pedindo a condenação deste ao pagamento de indenização por danos materiais em virtude dos prejuízos que sofreu em decorrência de acidente de trânsito. Suponhamos que na petição inicial Mário tenha alegado que não possui condições de arcar com as despesas do processo, bem como que Pedro dirigia em alta velocidade, costuma participar de rachas e trabalha como vendedor.

Neste caso hipotético, os fatos essenciais correspondem à prática de um ato ilícito culposo, ao dano sofrido e ao nexo de causalidade, conforme se depreende do modelo de fatos descrito nos arts. 186 e 927 do CC. São estes os fatos jurídicos que integram a causa de pedir e dos quais decorre, diretamente, a procedência ou improcedência da pretensão autoral, haja vista preencherem o suporte fático da norma a ser utilizada para resolver o caso.

Por sua vez, serão considerados fatos simples todos os demais: i) o argumento de Mário de que não possui condições de arcar com as despesas do processo está atrelado a uma técnica processual (benefício da gratuidade da justiça); ii) a alegação de que Pedro dirigia em alta velocidade é apenas uma maneira de demonstrar a sua culpa; iii) a assertiva de que o demandado costuma participar de rachas relaciona-se a indício de prova da sua culpa; iv) a afirmação de que Pedro trabalha com vendedor em nada se relaciona com o pedido reparatório de dano formulado.

Desse modo, a regra da eventualidade e a estabilização objetiva da demanda não impedirão que Mário alegue, no curso da demanda, que Pedro dirigia embriagado e que avançou o sinal vermelho, tendo vista tratar-se de fatos simples, os quais não alteram a causa de pedir inicialmente apresentada.

Da mesma forma, nova demanda proposta por Mário na qual ele alegue que Pedro dirigia embriagado e que avançou o sinal vermelho, com a formulação do mesmo pedido de indenização por danos materiais antes apresentado, esbarrará na coisa julgada, uma vez que a causa de pedir será a mesma que aquela deduzida anteriormente, tendo sido modificados tão somente os fatos secundários.

5 Causa de pedir próxima: fundamentos jurídicos, fundamentos legais e iura novit curia 
Malgrado a causa de pedir próxima não se preste a identificar a demanda, haja vista a adoção da teoria da substanciação no Brasil, não se pode olvidar da exigência feita pelo art. 319, inciso III, do CPC/2015 de indicação, na exordial, dos fundamentos jurídicos do pedido. O descumprimento deste requisito pode acarretar o indeferimento da petição inicial, conforme se depreende do art. 330, inciso IV, da legislação processual civil.

Convém não confundir fundamentos jurídicos, que consistem na afirmação de que os fatos narrados se enquadram em determinada categoria jurídica, com fundamento legal, que se refere à mera indicação dos dispositivos da lei. Nesse sentido, leciona Machado (2015, p. 8586):

\begin{abstract}
Outro ponto relevante reside na distinção feita pela doutrina, quanto ao conteúdo da causa de pedir próxima, entre fundamento jurídico e fundamento legal. O primeiro estaria relacionado às 'categorias jurídicas' aplicáveis ao caso, tais como a propriedade, a responsabilidade civil aquiliana, a responsabilidade contratual, a relação de paternidade, etc., que podem - em alguns casos - decorrer de diferentes dispositivos legais. O segundo seria um critério eminentemente formal, representado pela indicação das referências numéricas dos diplomas normativos (veículo de introdução das normas) que conteriam as normas jurídicas aplicáveis ao caso, tais como art. 1.228 do Código Civil, art. 927 do Código Civil, Cláusula X do Contrato, etc.
\end{abstract}

A exigência feita pelo $\mathrm{CPC} / 2015$ é de que o demandante enquadre os fatos por ele articulados em uma categoria jurídica (coação, por exemplo) que seja capaz de conduzi-lo à consequência pleiteada (anulação de negócio jurídico, por exemplo), sendo despiciendo o apontamento de artigos de lei (TALAMINI, 2005, p. 72).

Apesar de a indicação dos fundamentos jurídicos constituir ônus processual que recai sobre o demandante na elaboração da petição inicial, a fim de que ela seja considerada apta, o enquadramento dos fatos por ele narrados em uma determinada categoria jurídica não vincula o Estado-juiz, tratando-se de uma mera proposta ou sugestão (DINAMARCO, 2019, p. 153).

Essa desvinculação decorre da adoção, no Brasil, dos aforismos iura novit curia e $d a$ mihi factum dabo tibi ius, segundo os quais o juiz acha-se adstrito apenas aos fatos narrados e ao pedido formulado pelo demandante. Nesse sentido, leciona Lucca (2019, p. 314):

Literalmente, iura novit curia significa que juiz conhece os direitos. Adaptado ao atual estágio de desenvolvimento do Direito Processual e do Estado Moderno, devese traduzir o aforismo como "o juiz conhece o Direito" (que seria, na realidade, ius novit curia). De todo modo, o real significado da expressão é que o juiz deve pesquisar, enunciar e aplicar o direito no caso concreto, sem que haja qualquer vinculação ao que foi produzido e alegado pelas partes. 
Assim, há ampla liberdade para que o Poder Judiciário enquadre as alegações fáticas em categoria jurídica diversa daquela apresentada pelo autor, de modo a promover a adequada aplicação do direito objetivo (TUCCI, 2001, p. 162; TALAMINI, 2005, p. 72; SICA, 2011 p. 93-94; MACHADO, 2015, p. 87; DINAMARCO, 2019, p. 151-154).

Para ilustrar, imaginemos que uma pessoa natural tenha ajuizado demanda em face de uma fabricante de aparelho de telefonia móvel, alegando que o produto adquirido, repentinamente, após três dias de uso, parou de funcionar. Na petição inicial, a autora afirma que a ré agiu de forma negligente ao colocar no mercado produto de qualidade duvidosa, motivo pelo qual, aduzindo a existência de conduta culposa (na modalidade negligência), dano (de ordem material) e nexo de causalidade, pede o pagamento de indenização no valor do produto, embasando sua pretensão nos arts. 186 e 927 do CC.

Ao analisar o caso, o Estado-juiz não estará vinculado aos enunciados legislativos invocados pela autora, haja vista tratar-se de mero fundamento legal. Além disso, não haverá empecilhos para, sem se distanciar do pedido formulado, promover o enquadramento dos fatos que foram narrados em outra categoria jurídica.

No caso hipotético, a autora emoldurou suas alegações fáticas na categoria jurídica da responsabilidade civil subjetiva, segundo a qual, para que se possa cogitar de obrigação de indenizar, faz-se necessária a comprovação dos pressupostos da conduta ilícita culposa em sentido amplo, do dano e do nexo de causalidade.

Porém, ancorado no aforismo iura novit curia, o Estado-juiz poderá enquadrar os fatos narrados pela autora em outra categoria jurídica, da responsabilidade civil objetiva do fornecedor de produtos no mercado de consumo, que dispensa a comprovação de culpa. Ao proceder desta maneira, não estará se distanciando da causa de pedir remota apresentada, tendo em vista a estrita observância dos fatos essenciais deduzidos pela autora. Contudo, será indispensável o respeito ao contraditório, a fim de se evitar decisão surpresa (TUCCI, 2001, p. 163; DOMIT, 2018, p. 300-306; LUCCA, 2018, p. 367-372).

Por outro lado, se imaginarmos caso hipotético diverso, no qual os fatos narrados tenham sido enquadrados na categoria jurídica da responsabilidade civil objetiva, não será factível que o Estado-juiz promova o seu emolduramento na responsabilidade civil subjetiva se o demandante não tiver aludido ao elemento culpa na petição inicial, pois se assim o 
fizesse, estaria extrapolando os limites dos fatos essenciais que foram articulados, desrespeitando, consequentemente, a causa de pedir deduzida.

Percebe-se, portanto, que o Estado-juiz vincula-se apenas ao pedido e aos fatos expostos pelo demandante. Dentro destes limites, há liberdade para enquadrar as alegações fáticas em categoria jurídica distinta daquela sugerida na petição inicial (MACHADO, 2015, p. 87-88).

Dessa forma, é possível inferir que, para fins de identificação da causa de pedir, o foco deve ser direcionado aos fatos narrados. Porém, como já vimos, não são todos os fatos deduzidos pelo demandante que se prestam a identificar a causa petendi, devendo ser perquiridos aqueles considerados essenciais, isto é, capazes de produzir a consequência jurídica pretendida em virtude do seu enquadramento no modelo abstrato previsto pela norma de direito material relevante para o caso (MACHADO, 2015, p. 98).

Logo se nota que os fatos não são essenciais ou secundários por natureza, assumindo uma ou outra feição a depender da norma utilizada para fins de realização do seu emolduramento em uma determinada categoria jurídica.

É por isso que se fala em relatividade do fato essencial, conforme bem ressalta Domit (2018, p. 269):

\begin{abstract}
A essencialidade do fato, a sua proclamada juridicidade - assim como a sua secundariedade e irrelevância -, não é outra coisa senão o resultado da relação fatonorma estabelecida no processo. Isto é, o fato não é, por si só, essencial ou secundário, mas adquire uma ou outra dessas características no processo de qualificação jurídica realizado por meio da norma invocada como fundamento de direito da demanda. Assim, alterada a perspectiva normativa, modificado o suporte fático que ilumina a qualificação inicial dos fatos, a narrativa fática realizada, ainda que permaneça genuinamente idêntica, poderá ter a sua significância para o processo completamente alterada. Em outras palavras, a definição de um fato como 'jurídico' decorre de sua coincidência com o suporte fático da norma invocada, razão pela qual, modificada a norma aplicável, o novo suporte fático poderá transformar a circunstância antes descrita como essencial em secundária, e vice-versa.
\end{abstract}

Neste ponto, surge uma questão cujo esclarecimento se faz necessário. Trata-se de saber qual é a hipótese normativa que deve ser levada em consideração para, dentre os fatos narrados na petição inicial, identificar aquele que deve ser considerado essencial. É dizer, a norma invocada pelo demandante é primordial na identificação dos fatos essenciais? Há na doutrina ao menos duas correntes que buscam equacionar a questão (LOPES, 2012, p. 58-62). 
A primeira corrente apregoa que somente podem ser considerados essenciais os fatos que se ajustem ao suporte fático da norma jurídica invocada na petição inicial, sendo fatos simples todos os demais. Assim, embora o fundamento jurídico deduzido na prefacial não vincule o Estado-juiz, promove a delimitação de quais fatos podem ser tidos como essenciais, de modo que, ao aplicar o iura novit curia, o Poder Judiciário deve se atentar para não se valer de norma cujo suporte fático seja composto por elemento inexistente na fattispecie invocada na exordial ${ }^{3}$.

Pensamos que esta não é a melhor forma de enfrentar a questão, porquanto: i) reduz drasticamente a amplitude do aforismo iura novit curia, na contramão daquilo que é defendido por grande parte da brasileira; ii) inclui na causa de pedir os fatos e os fundamentos jurídicos, permitindo que, modificando-se qualquer desses elementos, seja alterada a demanda, o que acaba por restringir o alcance da coisa julgada (LOPES, 2012, p. 60); iii) confere ao demandante o poder de decidir o direito objetivo a ser aplicado ao caso, o que não se compatibiliza com a tradição brasileira e contraria o escopo jurídico do processo (LOPES, 2012, p. 83).

A seu turno, a segunda corrente defende que podem ser considerados essenciais quaisquer dos fatos narrados na exordial, independentemente da norma invocada pelo demandante, contanto que as alegações que ele formulou se enquadrem no suporte fático de alguma norma capaz de gerar as consequências jurídicas pretendidas.

Aderimos a segunda corrente porque, segundo pensamos: i) ela permite a ampla aplicação do aforismo iura novit curia; ii) preserva os contornos da teoria da substanciação, visto que circunscreve a causa de pedir aos fatos narrados pelo autor; iii) impede, por força da coisa julgada, o ajuizamento de demanda baseada em fato anteriormente já analisado como essencial ou simples (LOPES, 2012, p. 60-61; SIQUEIRA, 2018, p. 154-155).

Adotando-se a segunda corrente, conforme fazemos, tem-se que, se porventura, na petição inicial, o demandante enquadrar os fatos por ele narrados na responsabilidade civil

\footnotetext{
${ }^{3}$ Essa parece ser a posição de Domit (2018, p. 270-285), para quem o princípio da demanda não permite que o Estado-juiz, valendo-se do iura novit curia, modifique a qualificação jurídica realizada pelo demandante para o fim de tomar como secundários fatos que ele apontou serem essenciais, pois do contrário haveria ministração de tutela jurisdicional para uma situação jurídica que não foi articulada pelo autor (Iura novit curia..., p. 270-285). O raciocínio do autor baseia-se na sua compreensão de que a amplitude do iura novit curia é menor do que se costuma defender e de que a causa de pedir é identificada pelos fatos e pelos fundamentos jurídicos narrados na petição inicial. Essa forma de enxergar as coisas não se compatibiliza com a posição que assumimos no sentido de que o Brasil se filiou à teoria da substanciação, segundo a qual a causa petendi é individualizada exclusivamente pelos fatos.
} 
objetiva, mas descrever a prática de uma conduta culposa pelo demandado, o Estado-juiz terá ampla liberdade para, valendo-se do iura novit curia, enquadrar as alegações fáticas contidas na exordial em qualquer norma jurídica capaz de resultar o efeito jurídico pretendido.

Poderá, por exemplo, julgar o caso com base na responsabilidade civil subjetiva, ainda que o elemento culpa não integre o suporte fático da norma invocada inicial. Isso não caracterizará violação à regra da congruência, pois o Poder Judiciário não estará se distanciando dos fatos narrados pelo autor (a culpa foi narrada), mas apenas promovendo o seu emolduramento em outra norma jurídica.

Percebe-se, portanto, que por meio da aplicação do aforismo iura novit curia, é possível que fatos tidos pelo demandante como essenciais passem a ser secundários, e viceversa. A única limitação imposta ao Poder Judiciário será a observância dos fatos articulados e do pedido formulado (MACHADO, 2015, p. 102).

Segundo pensamos, essa variação na caracterização do fato como essencial ou simples em virtude da aplicação do aforismo iura novit curia não acarreta nulidade alguma, contanto que observado o contraditório prévio, a fim de se evitar a prolação de decisão surpresa.

Relativamente ao demandado, não se pode ignorar que sobre ele recai o ônus da impugnação especificada, motivo por que, na contestação, deve rebater todos os fatos narrados pelo demandado, não devendo se limitar a impugnar aquilo que considerar essencial, visto que sabe, de antemão, da possibilidade de o Estado-juiz promover a requalificação jurídica das alegações fáticas que constam na prefacial, fazendo com que um fato simples se torne essencial, e vice-versa (MACHADO, 2015, p. 103; SIQUEIRA, 2018, p. 154).

\section{Conclusão}

Em face do exposto, podemos concluir que: i) a análise sistemática do processo civil brasileiro evidencia que nos filiamos à teoria da substanciação, segundo a qual a causa de pedir é identificada pelos fatos narrados na exordial; ii) os fundamentos jurídicos invocados pelo autor não identificam a causa de pedir, consubstanciando-se em mera proposta ou sugestão de resolução do caso, que não vincula o Estado-juiz; iii) na causa de pedir remota, devem ser perquiridos os fatos essenciais, pois são eles que a individualizam; iv) o fato essencial é aquele que se amolda ao suporte fático da norma a ser utilizada no caso; v) o 
aforismo iura novit curia confere ao Estado-juiz ampla liberdade no emolduramento dos fatos narrados pelo autor em categoria jurídica diversa daquela por este proposta; vi) a requalificação jurídica que o Poder Judiciário pode realizar limita-se apenas ao pedido formulado e aos fatos (todos eles) articulados na inicial; vii) é plenamente possível que as alegações expostas pelo autor como principais assumam a feição secundária, e vice-versa, em virtude da ampla liberdade que o Estado-juiz tem de enquadrá-las em qualquer norma jurídica capaz de gerar as consequências pretendidas.

\section{Referências}

ABELHA, Marcelo. Manual de Direito Processual Civil. 6. ed. Rio de Janeiro: Forense, 2016.

ALVIM, Arruda. Manual de direito processual civil: processo de conhecimento. v. 2, 9. ed. São Paulo: Revista dos Tribunais, 2005.

BARBOSA MOREIRA, José Carlos. O novo processo civil brasileiro. 21. ed. Rio de Janeiro: Forense, 2001.

BUENO, Cássio Scarpinella. Curso sistematizado de direito processual civil: teoria geral do direito processual civil. v. 1. São Paulo: Saraiva, 2007.

CÂMARA, Alexandre Freitas. Lições de direito processual civil. v. 1. 24. ed. São Paulo: Atlas, 2013

CANOVA, Augusto Cerino. "La domanda giudiziale ed il suo contenuto". In: Commentario del Codice di Procedura Civile. vol. 2, t. I. Dirreto da Enrico Allorio. Torino: Utet, 1980.

CARVALHO, Milton Paulo de. Do pedido no processo civil. Porto Alegre: Fabris, 1992.

CHIOVENDA, Giuseppe. Instituiçoes de direito processual civil, v. I. Trad.: Paolo Capitanio. Bookseller: Campinas, 1998.

DINAMARCO, Cândido Rangel. Instituições de direito processual civil, v. II. 8. ed., rev. e atual., São Paulo: Malheiros, 2019.

DOMIT, Otávio Augusto Dal Molin. Iura novit curia e causa de pedir. São Paulo: Revista dos Tribunais, 2016.

FAZZALARI, Elio. Note in tema di diritto e processo. Milano: Giuffrè, 1957.

LEONEL, Ricardo de Barros. Causa de pedir e pedido: o direito superveniente. São Paulo: Método, 2006. 
LIEBMAN, Enrico Tullio. Manual de direito processual civil, v. 1, 3. ed. Trad.: Cândido Rangel Dinamarco. São Paulo: Malheiros, 2005.

LOPES, Bruno Vasconcelos Carrilho. Limites objetivos e eficácia preclusiva da coisa julgada. São Paulo: Saraiva, 2012.

LUCCA, Rodrigo Ramina de. Disponibilidade processual. Tese (doutorado). 2018. 449 f. Tese (Doutorado em Direito) - Programa de Pós-Graduação em Direito, Faculdade de Direito da Universidade de São Paulo, São Paulo.

MACHADO, Marcelo Pacheco. A correlação no processo civil: relações entre demanda e tutela jurisdicional. Salvador: JusPodivm, 2015.

MESQUITA, José Ignácio Botelho de. “A causa petendi nas ações reivindicatórias”. In: Teses, estudos e pareceres de processo civil. v. 1. São Paulo: Revista dos Tribunais, 2005.

OLIVEIRA, Carlos Alberto Alvaro. Do formalismo no processo civil. São Paulo: Saraiva, 1997.

OLIVEIRA, Bruno Silveira. Conexidade e efetividade processual. São Paulo: Revista dos Tribunais, 2007.

PONTES DE MIRANDA, Francisco Cavalcanti. Comentários ao código de processo civil. t. 2. 2. ed. Rio de Janeiro: Forense, 1974.

RICCI, Gian Franco. “'Individuazione' o 'sostanzione' nella riforma del processo civile”. In: Rivista trimestrale di dirtto e procedura civile, ano XLIX, n. 4, Milano: Giuffrè, 1995.

SANTOS, Moacyr Amaral. Primeiras linhas de direito processual civil. v. 2. 24 ed. São Paulo: Saraiva, 2008

SICA, Heitor Vitor Mendonça. $O$ direito de defesa no processo civil brasileiro: um estudo sobre a posição do réu. São Paulo: Atlas, 2011.

SIQUEIRA, Thiago Ferreira. Objeto do processo, questões prejudiciais e coisa julgada: análise dos requisitos para a formação de coisa julgada sobre a questão prejudicial incidental no Código de Processo Civil de 2015. 2018. 556 f. Tese (Doutorado em Direito) - Programa de Pós-Graduação em Direito, Faculdade de Direito da Universidade de São Paulo, São Paulo.

TALAMINI, Eduardo. Coisa julgada e sua revisão. São Paulo: Revista dos Tribunais, 2005.

TEIXEIRA, Guilherme Freire de Barros. O princípio da eventualidade no processo civil. São Paulo: Revista dos Tribunais, 2005.

TUCCI, José Rogério Cruz e. A causa petendi no processo civil. 2. ed. São Paulo: Revista dos Tribunais, 2001. 